\title{
Positive predictive value of the diagnosis coding for vitamin BI2 deficiency anemia in the Danish National Patient Register
}

This article was published in the following Dove Press journal:

Clinical Epidemiology

3 December 2012

Number of times this article has been viewed

\author{
Inès Ben Ghezala \\ Johan Frederik Berg Arendt \\ Rune Erichsen \\ Jihen Zalfani \\ Henrik Gammelager \\ Trine Frøslev \\ Morten Olsen
}

Department of Clinical Epidemiology, Aarhus University Hospital, Aarhus, Denmark
Correspondence: Johan Frederik Berg Arendt

Department of Clinical Epidemiology, Aarhus University Hospital, Olof Palmes Allé 43-45, 8200 Aarhus N, Denmark $\mathrm{Tel}+4587168063$

Fax +4587167215

Email johan.frederik.berg.arendt@sun.au.dk
Purpose: The aim of this validation study was to assess the positive predictive value (PPV) of the International Classification of Diseases, 10th revision (ICD-10) diagnosis of vitamin B12 (cobalamin [Cbl]) deficiency anemia in the Danish National Patient Register (DNPR).

Patients and methods: We identified all patients above 18 years of age recorded in the DNPR with a diagnosis of Cbl deficiency anemia (ICD-10 code: D51) admitted to two Danish university hospitals and one Danish regional hospital from 2000 through 2009. We assessed the PPV using biochemical parameters on $\mathrm{Cbl}$ deficiency with or without anemia as reference standards. These data were obtained from the Laboratory Information Systems Database. Data on prescriptions with Cbl supplementation drugs were obtained from the Aarhus University Prescription Database.

Results: We identified 1089 patients coded with a Cbl deficiency anemia diagnosis in the DNPR. The PPV was 31.5\% (95\% confidence interval [CI]: $28.8 \%-34.3 \%$ ) and $36.8 \%$ (95\% CI: $34.0 \%-39.7 \%$ ) depending on definitions of Cbl deficiency with anemia. When using $\mathrm{Cbl}$ deficiency without anemia as a reference standard, the PPV was $51.3 \%$ (95\% CI: 48.4\%-54.3\%) The PPV for Cbl supplemented patients was 22.2\% (95\% CI: 18.0\%-26.9\%) and for non-Cbl supplemented patients $63.9 \%$ (95\% CI: $60.5 \%-67.3 \%)$.

Conclusion: The PPVs of the ICD-10 diagnosis coding for Cbl deficiency anemia were generally low in the DNPR. Therefore, this register should be used with caution to study patients with $\mathrm{Cbl}$ deficiency anemia.

Keywords: vitamin B12 deficiency anemia, Danish National Patient Register, Laboratory Information Systems Database, International Classification of Diseases, positive predictive value, validation study

\section{Introduction}

Vitamin B12 (cobalamin [Cbl]) deficiency may lead to anemia ${ }^{1}$ and is usually caused by malabsorption in developed countries and by insufficient dietary intake in developing countries. ${ }^{2,3}$ The number of $\mathrm{Cbl}$ measurements and prescriptions for $\mathrm{Cbl}$ supplementation has increased in Denmark. ${ }^{4}$ This increasing awareness calls for valid data on this disease entity.

The Danish National Patient Register (DNPR) is a unique data source for research purposes and for quality assessment of the health care system. ${ }^{5}$ So far, no studies have assessed the validity of the $\mathrm{Cbl}$ deficiency anemia diagnosis in the DNPR.

Hence, the aim of this study was to assess the positive predictive value (PPV) of the International Classification of Diseases, 10th revision (ICD-10) diagnosis coding for Cbl deficiency anemia in the DNPR, using the Laboratory Information Systems (LABKA) Database ${ }^{6}$ as a reference standard. 


\section{Methods}

In this validation study, we identified all patients 18 years of age or older recorded in the DNPR with a first time inpatient or outpatient discharge diagnosis of $\mathrm{Cbl}$ deficiency anemia (ICD-10 code: D51). ${ }^{7}$ We included patients diagnosed at two university hospitals (Aarhus and Aalborg) and one regional hospital (Randers) in Denmark from January 1, 2000 to December 31, 2009.

The DNPR covers all somatic hospitals in Denmark and contains information on patients' civil registration numbers, dates of admission and discharge, code for hospital and department, and up to 20 discharge diagnoses coded by medical doctors according to ICD-8 (1977-1993) and ICD-10 (since 1994). In addition, selected types of hospitaladministered treatments are coded. We used the unique civil registration number assigned to all Danish residents to link individual-level data.

We linked patients with $\mathrm{Cbl}$ deficiency anemia recorded in the DNPR to the LABKA Database, our reference standard. LABKA contains information on all biochemical analyses performed in hospital laboratories in Northern and Central Denmark recorded according to Nomenclature, Properties, and Units (NPU) codes and/or local analysis numbers (see Table S1). The database has covered the study area since $2000 .^{6}$

No single diagnostic parameter exists for the biochemical diagnosis of $\mathrm{Cbl}$ deficiency. ${ }^{8}$ Measuring $\mathrm{Cbl}$ levels is routinely used, and methylmalonic acid (MMA) levels are used if the laboratory offers this analysis. Total homocysteine (tHcy) levels and mean corpuscular volume (MCV) can also be relevant when assessing $\mathrm{Cbl}$ deficiency. ${ }^{8}$ These issues complicated the definition of our reference standard and we therefore used both a "strict definition" and a "wide definition" of Cbl deficiency anemia, and Cbl deficiency without concomitant anemia. The three different definitions we operated with are outlined in Table 1.

Lower reference limits for anemia and $\mathrm{Cbl}$ deficiency were defined according to Danish reference limits. ${ }^{9,10}$ The algorithm for the biochemical assessment of $\mathrm{Cbl}$ deficiency is outlined in a review by Hvas and Nexo. ${ }^{11}$ This algorithm is widely implemented in Denmark. Briefly, the algorithm suggests measuring plasma $\mathrm{Cbl}$ levels first. Levels above $250 \mathrm{pmol} / \mathrm{L}$ rule out $\mathrm{Cbl}$ deficiency and levels below $125 \mathrm{pmol} / \mathrm{L}$ confirm the diagnosis. If the levels are between 125-250 pmol/L then MMA levels should be measured. MMA levels are divided into three categories: levels below $0.28 \mu \mathrm{mol} / \mathrm{L}$ rule out $\mathrm{Cbl}$ deficiency, levels above $0.75 \mu \mathrm{mol} / \mathrm{L}$ confirm $\mathrm{Cbl}$ deficiency, and levels between $0.28-0.75 \mu \mathrm{mol} / \mathrm{L}$ are inconclusive. We included the inconclusive ranges for $\mathrm{Cbl}$ and $\mathrm{MMA}^{12}$ in both our wide and strict definitions of $\mathrm{Cbl}$ deficiency. Thus, the defined ranges of values were wide enough to avoid missing any patients with $\mathrm{Cbl}$ deficiency. In the wide definition, we added tHcy and MCV as diagnostic parameters. We defined $12.0 \mu \mathrm{mol} / \mathrm{L}$ as the cut-off value for tHcy. It is the Danish upper reference limit for patients 30 years or older, modified according to a study by Rasmussen et al, ${ }^{12}$ since few patients in our study population were younger than 30 years. We defined macrocytosis as a $\mathrm{MCV}>98 \mathrm{fL}^{10}$

For each hospitalization, all blood samples taken between date of admission minus 3 months and date of discharge were examined for lowest hemoglobin levels, lowest Cbl levels, highest MMA levels, highest tHcy levels, and highest MCV, in case of multiple records.

We used the Aarhus University Prescription Database $(\mathrm{AUPD})^{13}$ to identify patients who redeemed Cbl supplementation prescriptions and the DNPR to identify in-hospital treatment with $\mathrm{Cbl}$. The AUPD contains the variables for civil registration number, name and ATC code of the drug, and date of prescription refill. It covers the study area and period. ${ }^{13}$ In Denmark, Cbl supplementation in therapeutic doses can only be obtained by a prescription. Prior use of $\mathrm{Cbl}$ was defined as one or more $\mathrm{Cbl}$ prescriptions or inhospital treatment with $\mathrm{Cbl}$ within 3 years before admission of the patient.

\section{Statistical analyses}

We computed PPVs as the proportion of patients identified with $\mathrm{Cbl}$ deficiency anemia in the DNPR who also had biochemical test results in the LABKA Database fulfilling the criteria of our reference standard definitions. We calculated PPVs for our three definitions of the reference standard: (1) strict and (2) wide definitions of $\mathrm{Cbl}$ deficiency anemia, and (3) Cbl deficiency without concomitant anemia. The analyses included all patients identified with a code of $\mathrm{Cbl}$ deficiency anemia in the DNPR, also those with no LABKA records. We stratified the analyses according to sex, age at diagnosis (18-39, 40-59, 60-79, 80+), calendar periods (2000-2005, 2006-2009), type of admission (inpatient, outpatient, or both admission types), and prior use of $\mathrm{Cbl}$ supplementation therapy. Patients with no LABKA records were included in the group of patients not fulfilling the diagnostic criteria. The PPVs are presented along with corresponding 95\% 
Table I Definitions used as reference standards for this validation study

\begin{tabular}{|c|c|c|}
\hline $\begin{array}{l}\text { Cbl deficiency anemia, strict definition } \\
\text { (I and }[A \text { or } B \text { or } C])\end{array}$ & $\begin{array}{l}\text { Cbl deficiency anemia, wide definition } \\
\text { ( } I \text { and }[A \text { or } B \text { or } C \text { or } D \text { or } E] \text { ) }\end{array}$ & $\begin{array}{l}\text { Cbl deficiency without concomitant } \\
\text { anemia (A or B or C or D or } E \text { ) }\end{array}$ \\
\hline $\begin{array}{l}\text { I. Hemoglobin }<7.0 \mathrm{mmol} / \mathrm{L} \\
(\text { women }) /<8.0 \mathrm{mmol} / \mathrm{L} \text { (men) }\end{array}$ & $\begin{array}{l}\text { I. Hemoglobin }<7.0 \mathrm{mmol} / \mathrm{L} \\
\text { (women) } /<8.0 \mathrm{mmol} / \mathrm{L} \text { (men) }\end{array}$ & \\
\hline A. $M M A>0.75 \mu \mathrm{mol}$ & A. $\mathrm{MMA}>0.75 \mu \mathrm{mol}$ & A. MMA $>0.75 \mu \mathrm{mol}$ \\
\hline B. Cbl $<125 \mathrm{pmol} / \mathrm{L}$ & B. $\mathrm{Cbl}<125 \mathrm{pmol} / \mathrm{L}$ & B. Cbl $<125 \mathrm{pmol} / \mathrm{L}$ \\
\hline C. $\mathrm{MMA}>0.28 \mu \mathrm{mol} / \mathrm{L}$ AND & C. $\mathrm{MMA}>0.28 \mu \mathrm{mol} / \mathrm{L}$ AND & C. MMA $>0.28 \mu \mathrm{mol} / \mathrm{L}$ AND \\
\hline \multirow[t]{4}{*}{ Cbl I25-250 pmol/L } & Cbl I25-250 pmol/L & Cbl I25-250 pmol/L \\
\hline & $\begin{array}{l}\text { D. Cbl I25-250 pmol/L AND } \\
\text { tHcy }>12.0 \mu \mathrm{mol} / \mathrm{L}\end{array}$ & $\begin{array}{l}\text { D. Cbl I25-250 } \mathrm{pmol} / \mathrm{L} \text { AND } \\
\text { tHcy }>12.0 \mu \mathrm{mol} / \mathrm{L}\end{array}$ \\
\hline & E. Cbl I25-250 pmol/L AND & E. Cbl I25-250 pmol/L AND \\
\hline & MCV > $98 \mathrm{fL}$ (macrocytosis) & MCV > $98 \mathrm{fL}$ (macrocytosis) \\
\hline
\end{tabular}

Notes: Definitions of cobalamin deficiency anemia and cobalamin deficiency without concomitant anemia. The fulfilling biochemical criteria are outlined. Abbreviations: Cbl, cobalamin; MCV, mean corpuscular volume; MMA, methylmalonic acid; thcy, total homocysteine.

confidence intervals (95\% CI), calculated according to Jeffrey's method. ${ }^{14}$ Analyses were performed using SAS version 9.2 (SAS Institute Inc, Cary, NC). The study was approved by The Danish Data Protection Agency (record number: 2005-41-5572).

\section{Results}

We identified 1089 patients with $\mathrm{Cbl}$ deficiency anemia according to the DNPR. The median age at diagnosis was 77 years, ranging from 18 to 102 years, and $62 \%$ were women. The proportion of patients without records in the LABKA Database was $4.5 \%$ for hemoglobin (anemia) and $4.7 \%$ for the $\mathrm{Cbl}$ related parameters.

The PPV for Cbl deficiency anemia was 31.5\% (95\% CI: $28.8 \%-34.3 \%)$ using the strict definition and $36.8 \%$ (95\% CI: $34.0 \%-39.7 \%$ ) using the wide definition (Table 2). The PPV using $\mathrm{Cbl}$ deficiency without concomitant anemia as a reference standard was overall 51.3\% (95\% CI: 48.4\%-54.3\%), varying from $22.2 \%$ (95\% CI: $18.0 \%-26.9 \%$ ) for patients with a prior $\mathrm{Cbl}$ use to $63.9 \%$ (95\% CI: $60.5 \%-67.3 \%$ ) for

Table 2 Positive predictive values for the coding of cobalamin deficiency anemia in the Danish National Patient Register

\begin{tabular}{|c|c|c|c|c|c|}
\hline & \multicolumn{2}{|c|}{ Cbl deficiency anemia } & \multicolumn{3}{|c|}{ Cbl deficiency without concomitant anemia } \\
\hline & \multicolumn{2}{|l|}{ PPV\% (95\% Cl) } & \multicolumn{3}{|l|}{ PPV\% (95\% Cl) } \\
\hline & Strict definition & Wide definition & All patients & With prior Cbl use & With no prior Cbl use \\
\hline Overall $(n=1089)$ & $31.5(28.8-34.3)$ & $36.8(34.0-39.7)$ & $51.3(48.4-54.3)$ & $22.2(18.0-26.9)$ & $63.9(60.5-67.3)$ \\
\hline \multicolumn{6}{|l|}{ Sex } \\
\hline Men $(n=409)$ & $42.1(37.3-46.9)$ & $47.7(42.9-52.5)$ & $59.7(54.8-64.3)$ & $31.6(22.9-41.4)$ & $68.2(62.9-73.1)$ \\
\hline Women $(n=680)$ & $25.1(22.0-28.5)$ & $30.3(26.9-33.8)$ & $46.3(42.6-50.1)$ & $18.4(\mid 3.8-23.7)$ & $61.0(56.4-65.4)$ \\
\hline \multicolumn{6}{|l|}{ Age at diagnosis } \\
\hline $18-39$ years $(n=116)$ & $34.5(26.3-43.4)$ & $38.8(30.3-47.8)$ & $69.0(60.2-76.8)$ & $45.5(26.3-65.7)$ & $74.5(65.0-82.4)$ \\
\hline $40-59$ years $(n=159)$ & $30.8(24.0-38.3)$ & $38.4(31.1-46.1)$ & $57.2(49.5-64.7)$ & $36.1(22.0-52.4)$ & $63.4(54.7-71.5)$ \\
\hline $60-79$ years $(n=347)$ & $33.1(28.3-38.2)$ & $38.9(33.9-44.1)$ & $52.4(47.2-57.7)$ & $22.3(15.4-30.7)$ & $66.8(60.6-72.6)$ \\
\hline $80+$ years $(n=467)$ & $29.8(25.8-34.0)$ & $34.3(30.1-38.7)$ & 44.I (39.7-48.6) & $15.7(\mid 0.7-22.0)$ & $58.8(53.2-64.2)$ \\
\hline \multicolumn{6}{|l|}{ Calendar period } \\
\hline 2000-2005 (n= 7II) & $29.4(26.1-32.8)$ & $34.9(31.4-38.4)$ & $49.2(45.6-52.9)$ & $20.7(15.8-26.4)$ & $62.2(57.8-66.4)$ \\
\hline $2006-2009(n=378)$ & $35.4(30.8-40.4)$ & $40.5(35.6-45.5)$ & $55.3(50.3-60.2)$ & $25.2(17.7-34.0)$ & $67.2(61.4-72.5)$ \\
\hline \multicolumn{6}{|l|}{ Patient type } \\
\hline Inpatient $(\mathrm{n}=629)$ & $31.5(27.9-35.2)$ & $36.6(32.9-40.4)$ & $43.6(39.7-47.5)$ & I4.I (9.8-19.4) & $57.2(52.5-61.8)$ \\
\hline Outpatient $(\mathrm{n}=308)$ & $25.6(21.0-30.7)$ & $30.2(25.3-35.5)$ & $63.0(57.5-68.2)$ & $41.9(31.8-52.4)$ & $71.2(65.0-76.8)$ \\
\hline $\begin{array}{l}\text { Both inpatient and } \\
\text { outpatient }(n=152)\end{array}$ & $43.4(35.7-5 \mid .4)$ & $51.3(43.4-59.2)$ & $59.9(52.0-67.4)$ & $20.5(10.6-34.0)$ & $75.9(67.3-83.2)$ \\
\hline
\end{tabular}

Notes: PPVs are computed using three different reference standards defined by laboratory data from the LABKA Database. For definitions of reference standards see Table I. Abbreviations: Cbl, cobalamin; Cl, confidence interval; DNPR, Danish National Patient Register; LABKA, Laboratory Information Systems Database; PPV, positive predictive value. 
patients with no prior $\mathrm{Cbl}$ use. In general, PPVs were higher for men than for women.

\section{Discussion}

We studied the validity of coding for Cbl deficiency anemia in the DNPR and generally found low PPVs. This may reflect a potential clinical use of this code for $\mathrm{Cbl}$ deficiency independent of anemia as there is no specific ICD-10 code for this condition.

There is no previous investigation of the validity of the ICD-10 diagnosis coding for $\mathrm{Cbl}$ deficiency anemia in the DNPR. Other validation studies of ICD-10 diagnosis coding in the DNPR have shown PPVs of $90 \%$ or higher, ${ }^{15-18}$ although only one of these have investigated diseases or conditions that required laboratory data as a reference standard. ${ }^{15}$

There are several limitations inherent to the definition of a reference standard for $\mathrm{Cbl}$ deficiency anemia and the following should be considered when interpreting the results. Our data may indicate that physicians use the ICD-10 code for Cbl deficiency anemia, D51, when patients have had $\mathrm{Cbl}$ deficiency anemia in the past. These patients may have normal hemoglobin and/or Cbl related parameters at the time of coding in the DNPR. Accordingly, the PPV was lower among patients with prior use of $\mathrm{Cbl}$ supplementation compared with patients with no prior use.

The performances of different biochemical parameters in diagnosing $\mathrm{Cbl}$ deficiency have been thoroughly characterized, including the measurement of holotranscobalamin, the metabolically active fraction of circulating Cbl. ${ }^{19-22}$ Based on these investigations, strategies have been suggested on how to diagnose $\mathrm{Cbl}$ deficiency by assessing biochemical results. ${ }^{19,21}$ In the future, these strategies may lead to improvements in the diagnosis of $\mathrm{Cbl}$ deficiency.

Furthermore, from these investigations, it is evident that a single blood test result is not definitive in the diagnosis of $\mathrm{Cbl}$ deficiency. ${ }^{8}$ To address this, we included several parameters in the reference standards that are all applicable for diagnosing $\mathrm{Cbl}$ deficiency. ${ }^{8}$ Furthermore, physicians may diagnose $\mathrm{Cbl}$ deficiency anemia on the basis of symptoms or prior knowledge of the individual patient despite dismissive laboratory results. This would clinically be considered correct according to the current guidelines, as described by Hvas and Nexo. ${ }^{11}$ On the basis of these considerations, we may also have underestimated the PPV when using laboratory test results. In addition, we were not able to estimate the sensitivity of the coding of $\mathrm{Cbl}$ deficiency anemia since the true prevalence was unknown.

\section{Conclusion}

The PPVs of the ICD-10 diagnosis coding for Cbl deficiency anemia were generally low in the DNPR. Our data indicated that this register should be used with caution in studies on Cbl deficiency anemia.

\section{Disclosure}

The authors report no conflicts of interest in this work. This study received financial support from the Department of Clinical Epidemiology's Research Foundation. The Department of Clinical Epidemiology, Aarhus University Hospital, receives funding for other studies from companies in the form of research grants to (and administered by) Aarhus University. None of these studies have any relation to the present study.

\section{References}

1. de Benoist B. Conclusions of a WHO Technical Consultation on folate and vitamin B12 deficiencies. Food Nutr Bull. 2008;29(Suppl 2): S238-S244.

2. Stabler SP, Allen RH. Vitamin B12 deficiency as a worldwide problem. Annu Rev Nutr. 2004;24:299-326.

3. Dali-Youcef N, Andrès E. An update on cobalamin deficiency in adults. QJM. 2009;102(1):17-28.

4. Hvas AM, Ellegaard J, Nexø E. Diagnosis of vitamin B12 deficiency-time forreflection. Ugeskr Laeger. 2003;165(19):1971-1976.

5. Lynge E, Sandegaard JL, Rebolj M. The Danish National Patient Register. Scand J Public Health. 2011;39(Suppl 7):S30-S33.

6. Grann AF, Erichsen R, Nielsen AG, Frøslev T, Thomsen RW. Existing data sources for clinical epidemiology: the clinical laboratory information system (LABKA) research database at Aarhus University, Denmark. Clin Epidemiol. 2011;3:133-138.

7. International Statistical Classification of Diseases and Related Health Problems, 10th Revision, Version for 2007 [webpage on the Internet]. Geneva: World Health Organization; 2010. Available from: http://apps. who.int/classifications/apps/icd/icd10online/. Accessed August 1, 2011.

8. Herrmann W, Obeid R. Cobalamin deficiency. Subcell Biochem. 2012; 56:301-322.

9. Analysis and reference interval in the Central and Northern Denmark regions. Available from: https:/www.itsundhed.dk/laboratorie_liste/ Prog/d_udskriftsvenlig_udgave.aspx?id=179. Accessed August 3, 2012.

10. Nordin G, Mårtensson A, Swolin B, et al. A multicentre study of reference intervals for haemoglobin, basic blood cell counts and erythrocyte indices in the adult population of the Nordic countries. Scand J Clin Lab Invest. 2004;64(4):385-398.

11. Hvas AM, Nexo E. Diagnosis and treatment of vitamin B12 deficiency - an update. Haematologica. 2006;91(11):1506-1512.

12. Rasmussen K, Møller J, Lyngbak M, Pedersen AM, Dybkjaer L. Age- and gender-specific reference intervals for total homocysteine and methylmalonic acid in plasma before and after vitamin supplementation. Clin Chem. 1996;42(4):630-636.

13. Ehrenstein V, Antonsen S, Pedersen L. Existing data sources for clinical epidemiology: Aarhus University Prescription Database. Clin Epidemiol. 2010;2:273-279.

14. Brown LD, Cai TT, DasGupta A. Interval estimation for a binomial proportion. Stat Sci. 2001;16(2):101-133.

15. Heden KE, Jensen AØ, Farkas DK, Nørgaard M. Validity of a procedure to identify patients with chronic idiopathic thrombocytopenic purpura in the Danish National Registry of Patients. Clin Epidemiol. 2009;1:7-10. 
16. Erichsen R, Strate L, Sørensen HT, Baron JA. Positive predictive values of the International Classification of Disease, 10th edition diagnoses codes for diverticular disease in the Danish National Registry of Patients. Clin Exp Gastroenterol. 2010;3:139-142.

17. Helqvist L, Erichsen R, Gammelager H, Johansen MB, Sørensen HT. Quality of ICD-10 colorectal cancer diagnosis codes in the Danish National Registry of Patients. Eur J Cancer Care (Engl). 2012;21(6): $722-727$.

18. Gammelager H, Christiansen CF, Johansen MB, Borre M, Schoonen M, Sørensen HT. Quality of urological cancer diagnoses in the Danish National Registry of Patients. Eur J Cancer Prev. 2012;21(6):545-551.

19. Carmel R. Biomarkers of cobalamin (vitamin B-12) status in the epidemiologic setting: a critical overview of context, applications, and performance characteristics of cobalamin, methylmalonic acid, and holotranscobalamin II. Am J Clin Nutr. 2011;94(1):348S-358S.
20. Chatthanawaree W. Biomarkers of cobalamin (vitamin B12) deficiency and its application. J Nutr Health Aging. 2011;15(3):227-231.

21. Valente E, Scott JM, Ueland PM, Cunningham C, Casey M, Molloy AM. Diagnostic accuracy of holotranscobalamin, methylmalonic acid, serum cobalamin, and other indicators of tissue vitamin B12 status in the elderly. Clin Chem. 2011;57(6):856-863.

22. Nexo E, Hoffmann-Lücke E. Holotranscobalamin, a marker of vitamin B-12 status: analytical aspects and clinical utility. Am J Clin Nutr. 2011;94(1):359S-365S. 


\section{Supplementary material}

Table SI Analysis codes used in this validation study

\begin{tabular}{llll}
\hline Database & Parameter searched & Type of analysis codes & Analysis codes \\
\hline LABKA Database & Hemoglobin & NPU & 023I9, 0232I, 2I690 \\
& & DaAish laboratory codes & ASS00I26, ASS00996 \\
& Methylmalonic acid & NPU & 02780 \\
& Total homocysteine & NPU & 04073 \\
& & Danish laboratory codes & AAA00705 \\
& Mean corpuscular volume & NPU & 01944 \\
& Cbl deficiency diagnostics & Danish laboratory codes & AAA0028I, AAA00304 \\
& & NPU & 0 I700 \\
AUPD & ATC supplementation & & AIIE, B03BA0I, B03BA02, \\
& prescriptions & & B03BA03, V03AB33 \\
DNPR & Hospital administered Cbl & & BOHC2 \\
& supplementation administration & & \\
\hline
\end{tabular}

Abbreviations: ATC, anatomical therapeutic chemical; AUPD, Aarhus University Prescription Database; Cbl, cobalamin; DNPR, Danish National Patient Register; LABKA, Laboratory Information Systems Database; NPU, Nomenclature, Properties, and Units.

\section{Publish your work in this journal}

Clinical Epidemiology is an international, peer-reviewed, open access journal focusing on disease and drug epidemiology, identification of risk factors and screening procedures to develop optimal preventative initiatives and programs. Specific topics include: diagnosis, prognosis, treatment, screening, prevention, risk factor modification, systematic

Submit your manuscript here: http://www.dovepress.com/clinical-epidemiology-journal reviews, risk \& safety of medical interventions, epidemiology \& biostatical methods, evaluation of guidelines, translational medicine, health policies \& economic evaluations. The manuscript management system is completely online and includes a very quick and fair peer-review system, which is all easy to use. 